\section{Femtosecond Absorption Spectroscopy of Transition Metal Charge-Transfer Complexes}

JAMES K. MCCUSKER

Department of Chemistry, Michigan State University, East Lansing, Michigan 48824

Received May 6, 2003

\section{ABSTRACT}

Our research is concerned with the application of femtosecond time-resolved absorption techniques to the study of the photophysics of transition metal complexes. The focus is to understand the events that characterize the process of excited-state evolution from the time a photon is absorbed by a molecule to the formation of the lowest-energy excited state of the system. This Account describes our initial observations in this area and includes examples detailing these dynamics as they occur in the charge-transfer excited states of transition-metal polypyridyl chromophores.

\section{Introduction}

The process of charge separation is the physical phenomenon underlying virtually all schemes geared toward the conversion of light into chemical, electrical, and/or mechanical energy. For example, in photosynthesis, absorption of light by either the light-harvesting complex or the reaction center itself sets the stage for producing a transmembrane potential gradient: this ultimately provides the chemical energy for ATP synthase. In materials science, where semiconductors are the functional element of most photovoltaic devices, absorption of light leads to the formation of electron-hole pairs that result in the establishment of an electric potential. Recent work by a number of groups has demonstrated the viability, at least in principle, of so-called molecular machines that harness the energy gained through photoinduced charge separation to trigger a range of mechanical responses at the molecular level. ${ }^{1}$ In all such cases, the requisite first step is the absorption of a photon to alter the charge distribution within the chromophore: maintaining, amplifying, or, in the least favorable circumstances, destroying the resulting chemical potential depends on dynamics that occur within the chromophore immediately following the absorptive event.

I im McCusker was born in New Haven, Connecticut, in 1965. He obtained a B.S./M.S. degree from Bucknell University in 1987, working with Charles A. Root on oxovanadium chemistry. In 1992, McCusker received his Ph.D. from the University of Illinois with David N. Hendrickson, studying the magnetic properties of polynuclear $\mathrm{Mn}$ and Fe clusters in addition to the spin-crossover dynamics of Fe(II) complexes. From 1992 to 1994, he was an NIH postdoctoral fellow with Professor Thomas J. Meyer at the University of North Carolina at Chapel Hill. McCusker began his independent career as an Assistant Professor at the University of California at Berkeley in 1994. In J anuary 2001, he moved his research group to Michigan State University, where he is currently Associate Professor of Chemistry. The author's research focuses on the ultrafast spectroscopy of transition metal complexes as well as electron exchange effects on electron and energy transfer dynamics.

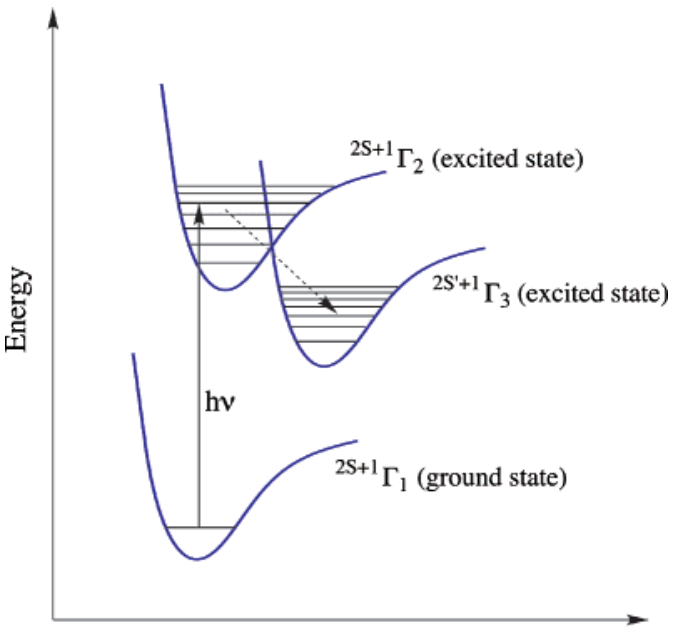

Nuclear coordinate (Q)

FIGURE 1. Generalized potential energy surface diagram for excitedstate evolution. Initial excitation from the ground state ${ }^{25+1} \Gamma_{1}$, where $S$ denotes the spin state) to the higher-lying excited state $\left(25+1 \Gamma_{2}\right)$ is followed by relaxation to the lower-energy surface $\left({ }^{25^{\prime}+1} \Gamma_{3}\right)$. Understanding the dynamics and mechanism of the ${ }^{25+1} \Gamma_{2} \rightarrow 25^{\prime}+1 \Gamma_{3}$ conversion as it occurs in transition-metal charge-transfer complexes is the focus of the research described in this Account.

Inorganic compounds have long been exploited in the study of photoinduced charge-transfer processes ${ }^{2}$ as well as the quest for achieving efficient solar energy conversion. ${ }^{3}$ The three-level system depicted in Figure 1 , while simplistic, is a reasonably good model for most inorganic chromophores when considering the formation of longlived (i.e., nanosecond or longer) excited state(s) that are potentially redox-active. In general, in order for these lower-energy excited states to engage in chemistry, there must be a significant barrier associated with ground-state recovery. A typical example of this would be a spinforbidden transition (i.e., where $S \neq \mathrm{S}^{\prime}$ ). However, the same quantum-mechanical restrictions that can slow the rate of excited-state relaxation back to the ground state very often prevent initial, direct access to that state via photon absorption. Formation of the desired reactive state then relies on a sequence of events: excitation into an upper level having significant radiative coupling to the ground state, followed by relaxation to the lower-energy state(s). A host of dynamic processes are potentially involved in this process, among them intersystem crossing (ISC), internal conversion (IC), vibrational relaxation, and/ or intramolecular vibrational redistribution, as well as solvation dynamics. Efforts over the past several decades have helped to forge our understanding of the dynamics of the lowest-energy excited states of inorganic systems at an impressive level of sophistication; however, details concerning the processes by which these states are formed in the first place remain largely obscure.

It is these initial relaxation dynamics as they occur in transition-metal-containing charge-transfer complexes that are the focus of this Account. Our research on the ultrafast dynamics of metal complexes is geared toward addressing the following four questions: (1) What is the 
time scale of the formation of low-energy excited states following photoexcitation? (2) What are the nature and dynamics of the processes involved in this excited-state evolution? (3) What correlations can we establish between these dynamics and the geometric and electronic properties of the molecules, as well as other variables such as temperature, pressure, the solvent, etc.? And finally, (4) Given this knowledge, to what extent can we manipulate these various processes through synthetic or other means in order to effect some measure of control over chargetransfer state formation and/or reactivity? It can be anticipated at the outset that the processes of interest lie in a temporal regime largely irrelevant for those interested in bimolecular reactions, e.g., picoseconds to femtoseconds. However, data emerging from a number of groups continue to underscore the importance of nonthermalized excited states in dictating a broad range of excited-state reactivity from the earliest moments following photoexcitation. ${ }^{4}$ The dynamics that we are investigating comprise the mechanistic details of what occurs following photon absorption, and in this regard are of importance for processes concomitant with and subsequent to excited-state formation.

\section{The Prototype: $\left[\mathrm{Ru}(\mathrm{bpy})_{3}\right]^{2+}$}

By far the most frequently employed inorganic chromophores for photoinduced charge separation are the polypyridyl complexes of Group 8. [Ru(bpy $\left.)_{3}\right]^{2+}$, where bpy is 2,2'-bipyridine, can be considered the prototype of this class of compounds. Their extensive use in settings ranging from light harvesting in dendritic polymers 5 to the sensitization of wide band-gap semiconductors ${ }^{3 a}$ testifies to the important role such compounds continue to play in molecular solar energy research. $\left[\mathrm{Ru}(\mathrm{bpy})_{3}\right]^{2+}$ therefore provides the natural starting point for the study of ultrafast dynamics in inorganic charge-transfer complexes. The

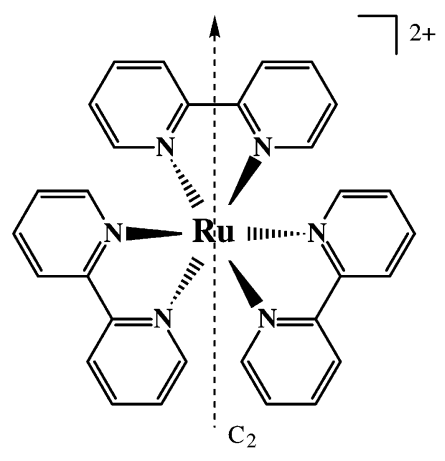

electronic structure of this compound has been described in considerable detail; ${ }^{6}$ however, the simple potential energy diagram in Figure 1 provides a reasonable framework for thinking about excited-state evolution in this system. The ground state of the compound is a singlet $\left({ }^{1} A_{1} \equiv{ }^{25+1} \Gamma_{1}\right.$ in Figure 1$)$ and exhibits an absorption near $450 \mathrm{~nm}$; the extinction coefficient of $\sim 10^{4} \mathrm{M}^{-1} \mathrm{~cm}^{-1}$ supports its assignment as a spin-allowed metal-to-ligand charge transfer $\left({ }^{1} \mathrm{MLCT} \equiv{ }^{25+1} \Gamma_{2}\right)$. The compound possesses an emissive excited state with a lifetime of ca. $1 \mu \mathrm{s}$.

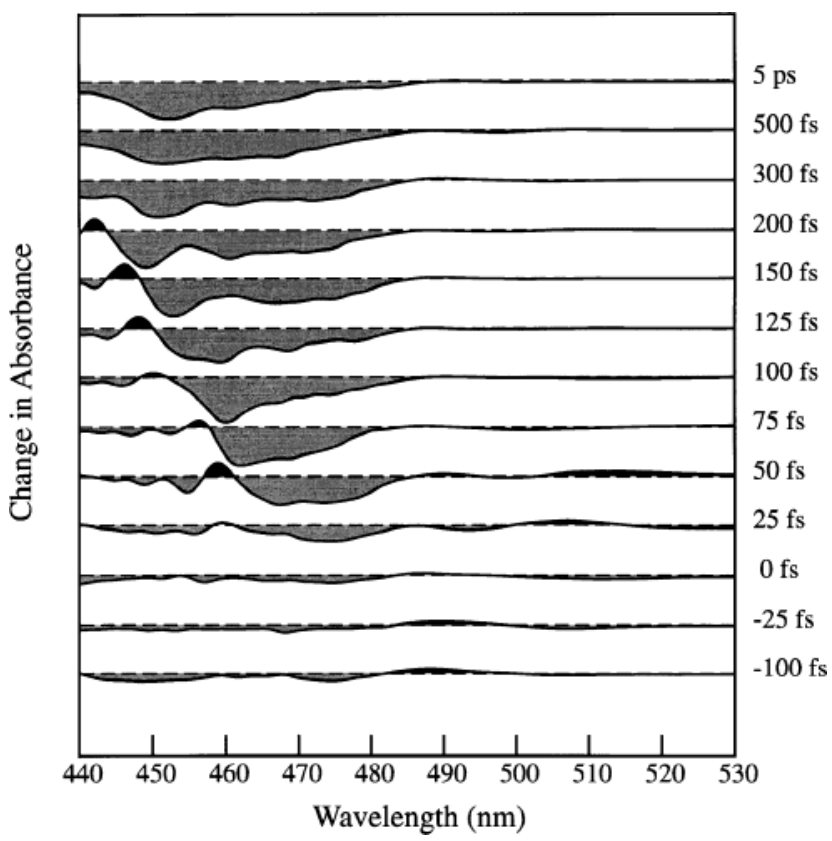

FIGURE 2. Transient differential absorption spectra for $\left[\mathrm{Ru}(\mathrm{bpy})_{3}\right]^{2+}$ in $\mathrm{CH}_{3} \mathrm{CN}$ solution following $\sim 25$ fs excitation at $480 \mathrm{~nm}$. These data reflect the change in the absorbance of the compound $(\Delta A)$ relative to the ground state due to photoexcitation and subsequent formation of excited state(s). The numbers to the right of each spectrum correspond to its acquisition time relative to the excitation pulse. Each horizontal line indicates $\Delta A=0$ at the specified delay time: Lightly shaded regions below each line therefore represent a bleach, whereas darker shaded regions above the line reflect a net increase in sample absorbance. (Adapted from ref 8.)

The solvatochromic behavior of this emission, coupled with a relatively low radiative decay rate of $\sim 10^{5} \mathrm{~s}^{-1}$, leads to its assignment as a ${ }^{3} \mathrm{MLCT} \rightarrow{ }^{1} \mathrm{~A}_{1}$ transition ( ${ }^{3} \mathrm{MLCT} \equiv$ $\left.{ }^{2 S^{\prime}+1} \Gamma_{3}\right)$. Previous studies of this compound using picosecond time-resolved spectroscopies were only able to establish a lower limit of $\sim 10^{11} \mathrm{~s}^{-1}$ for the formation of the ${ }^{3}$ MLCT. ${ }^{7}$ Our first task, then, pursuant to point (1) in the Introduction, was to determine the time scale of ${ }^{3} \mathrm{MLCT}$ formation in $\left[\mathrm{Ru}(\mathrm{bpy})_{3}\right]^{2+}$.

Femtosecond time-resolved absorption measurements of $\left[\mathrm{Ru}(\mathrm{bpy})_{3}\right]^{2+}$ in $\mathrm{CH}_{3} \mathrm{CN}$ solution following $\sim 25 \mathrm{fs}$ excitation at $480 \mathrm{~nm}$ are illustrated in Figure $2 .{ }^{8}$ It can be seen that, immediately following excitation, the molecule exhibits a loss of absorbance (i.e., a bleach). Although the spectral changes apparent for the first 200 fs reflect specific processes associated with excited-state evolution, our initial interest is the point in time at which these spectral dynamics cease: this is our principal (but not necessarily absolute) indication that changes in the electronic structure of the compound are complete. Inspection of the data shows that, for all time delays $\geq 300 \mathrm{fs}$, no additional changes in the differential absorption profile are noted. Furthermore, the difference spectrum collected on the nanosecond time scale, which samples the fully relaxed ${ }^{3} \mathrm{MLCT}$ state, is superimposable with all spectra acquired for $\Delta t>300 \mathrm{fs}$. These data allow us to ascribe a value of $\sim 100$ fs for the formation time of the ${ }^{3} \mathrm{MLCT}$ state of $\left[\mathrm{Ru}(\mathrm{bpy})_{3}\right]^{2+}$ in $\mathrm{CH}_{3} \mathrm{CN}$ solution. ${ }^{9}$ 
It is important to emphasize that the time constant implied by the spectra in Figure 2 does not necessarily correspond to an intersystem crossing rate, but rather to an overall time scale for formation of the ${ }^{3 M L C T}$ state. Intersystem crossing, which can be thought of as the point during excited-state evolution when the wave function loses singlet character and acquires triplet character, is presumably contained within these dynamics. However, transient absorption spectroscopy is not necessarily a selective probe for the spin change itself. ${ }^{10}$ Okada and coworkers have recently reported femtosecond fluorescence upconversion data on $\left[\mathrm{Ru}(\mathrm{bpy})_{3}\right]^{2+}$ in several solvents. ${ }^{11}$ This experiment is potentially more discriminating for the actual intersystem crossing event, since radiative coupling back to the ground state (the source of the upconversion signal) is strongly dependent on a change of spin in the excited state. Given the large radiative rate necessary to achieve upconversion, the decrease in emission intensity that Okada observes is wholly consistent with a singlet $\rightarrow$ triplet excited-state conversion. The $40 \pm 15$ fs time constant they report is therefore what we believe should be regarded as the time scale for ISC in $\left[R u(b p y)_{3}\right]^{2+}$ in solution. The data in Figure 2 instead sample a much broader range of dynamics associated with the overall evolution from the ${ }^{1} \mathrm{MLCT}$ Franck-Condon state to the thermalized ${ }^{3} \mathrm{MLCT}$ excited state.

\section{Laying the Groundwork for Ultrafast Measurements: Static and Nanosecond Time-Resolved Spectroscopies}

The critically important role played by more conventional spectroscopies (e.g., static and nanosecond methods) in support of femtosecond time scale studies cannot be overstated. For example, the spectroscopic properties of the long-lived excited state provide the optical signatures required for determining when electronic state evolution is complete. We have found it essential that the nature of the Franck-Condon state, the lowest-energy excited state, and the absorption characteristics of the chromophore be thoroughly characterized prior to the analysis of femtosecond time-resolved data.

The Franck-Condon State. To track the earliest stages of excited-state dynamics, one needs to know what amounts to the starting point for the whole process, i.e., the Franck-Condon state. A rough idea as to the nature of the Franck-Condon state (e.g., charge-transfer, ligandfield, etc.) can be inferred from the oscillator strength of the transition. ${ }^{12}$ This approach becomes more difficult with second- and third-row metal complexes due to increased metal-ligand covalency as one goes down the periodic table (thus blurring the distinction between ligand-field and charge-transfer transitions), as well as the increase in spin-orbit coupling. ${ }^{13}$ Single-crystal absorption spectra can be helpful in making assignments due to the polarization information it affords, but such measurements can become complete research projects in their own right.

One computational approach that appears quite promising is time-dependent density functional theory (TD-

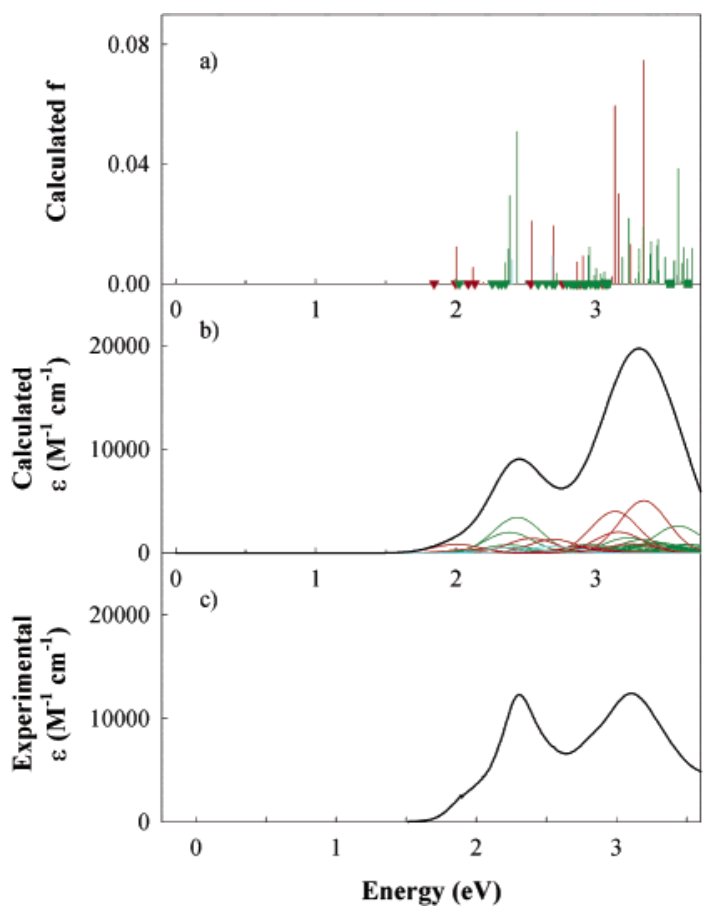

FIGURE 3. Calculated and experimental visible absorption spectra of $\left[\mathrm{Ru}(\mathrm{dcbpy})_{2}(\mathrm{NCS})_{2}\right]^{4-}$ (a) Oscillator strengths ( $f$ ) of electronic transitions determined by a time-dependent density functional theory (TD-DFT) calculation. The red and green lines correspond to spinallowed transitions that are predominantly M LCT and ligand-based in character, respectively; the black lines are transitions where the M LCT and ligand-based contributions are comparable. Solid triangles correspond to spin-fobidden transitions which have $f=0$ in the limit of no spin-orbit coupling. (b) Calculated absorption spectrum of $\left[\mathrm{Ru}(\mathrm{dcbpy})_{2}(\mathrm{NCS})_{2}\right]^{4-}$. This spectrum was generated assuming a $0.4 \mathrm{eV}$ bandwidth for each transition and fixing the area under the Gaussian to be proportional to its calculated oscillator strength. The dashed curve represents the sum of all of these calculated features. (c) Experimental absorption spectrum of Ru(dcbpy $)_{2}(\mathrm{NCS})_{2}$ in $\mathrm{EtOH}$ solution. The spectra in (a) and (b) have been uniformly offset by $0.146 \mathrm{eV}$ in order to facilitate the comparison of relative peak positions with the experimental spectrum. (Adapted from ref 15.)

DFT). ${ }^{14}$ Application of this methodology can provide insight into the orbital nature of electronic excited states in transition metal systems that is difficult to obtain by other means. For example, we have carried out a TD-DFT calculation on $\left[\mathrm{Ru}(\mathrm{dcbpy})_{2}(\mathrm{NCS})_{2}\right]^{4-}$ (where dcbpy ${ }^{2-}$ is the doubly deprotonated form of 4,4'-dicarboxylic acid-2,2' bipyridine). ${ }^{15}$ Using only the single-crystal X-ray structure of the compound as input, we were able to calculate the absorption spectrum of the compound to a significant degree of accuracy (Figure 3). By examining the composition of the multielectron states involved in each transition, an orbital-level description of the visible absorption features of the molecule was obtained. This in turn helped to shape our thinking about the mechanism of charge injection in photovoltaic devices employing this molecule as a sensitizer. ${ }^{15,16}$ It seems likely that as these and related ${ }^{17}$ computational methods continue to evolve, they will become an important tool in the interpretation of ultrafast spectroscopic data.

Identifying the Lowest-Energy Excited State. The need for collecting and analyzing static and nanosecond time- 

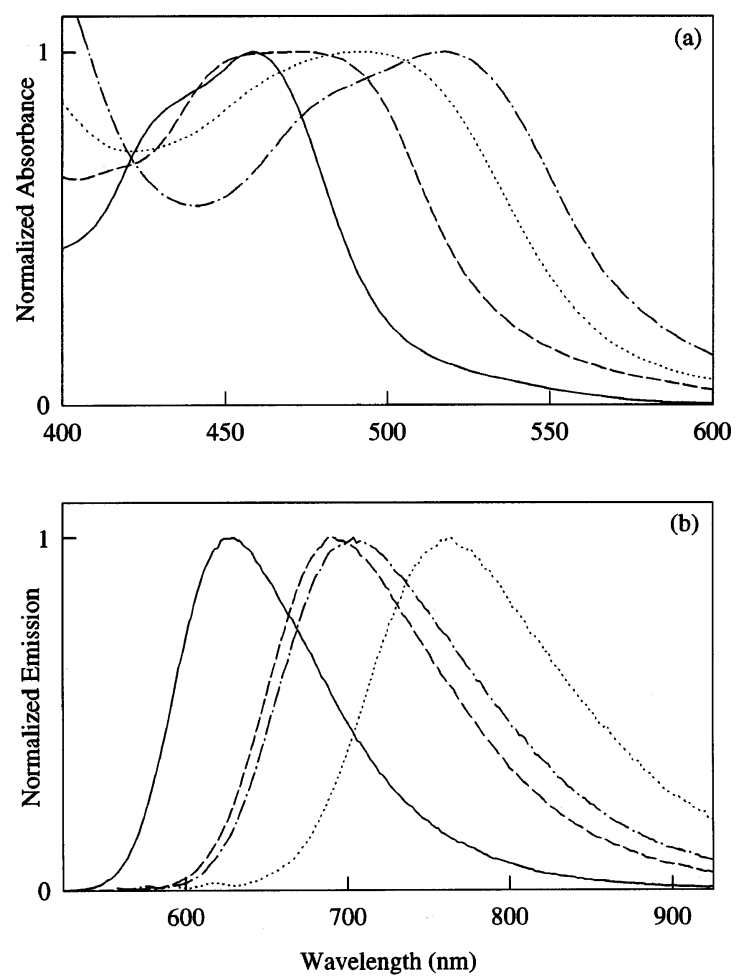

FIGURE 4. (a) Electronic absorption spectra of $\left[\mathrm{Ru}(\mathrm{dmb})_{3}\right]^{2+}(-)$, $\left[\mathrm{Ru}(\mathrm{dmb})_{2}(\mathrm{dea})\right]^{2+}(---),\left[\operatorname{Ru}(\mathrm{dmb})(\mathrm{dea})_{2}\right]^{2+}(\cdots)$, and $\left[\mathrm{Ru}(\mathrm{dea})_{3}\right]^{2+}$ $(--)$, all in $\mathrm{CH}_{3} \mathrm{CN}$ solution. (b) Static room-temperature emission spectra for $\left[\mathrm{Ru}(\mathrm{dmb})_{3}\right]^{2+}(-),\left[\operatorname{Ru}(\mathrm{dmb})_{2}(\mathrm{dea})\right]^{2+}(---),[\operatorname{Ru}(\mathrm{dmb})-$ $\left.(\text { dea })_{2}\right]^{2+}(\cdots)$, and $\left[\mathrm{Ru}(\text { dea })_{3}\right]^{2+}(-\cdot-)$, all in deoxygenated $\mathrm{CH}_{3} \mathrm{CN}$ solution. (Adapted from ref 18.)

resolved data in order to unambiguously establish the nature of the lowest-energy excited state of a compound was made particularly evident in one case involving lowsymmetry chromophores. Following photon absorption, excited-state evolution generally leads to population of the lowest-energy excited state of the molecule. In asymmetric molecules, this state may or may not be associated with the charge-transfer manifold that was initially excited. Complexes where this is an issue are those having the general form $\left[R u\left(b p y^{\prime}\right)_{x}\left(b_{p y}{ }^{\prime \prime}\right)_{3-x}\right]^{2+}(x=0-3)$, where bpy' and bpy" are 2,2'-bipyridyl moieties with differing substituents at various positions on the pyridyl rings. We carried out a detailed study of the electronic structure of one such system, $\left[R u(d m b)_{x}(d e a)_{3-x}\right]^{2+}$, where $d m b$ is 4,4'dimethyl-2,2'-bipyridine and dea is 4,4'-diethylamino-2,2'bipyridine. ${ }^{18}$ The broadening of the absorption spectrum at low energy following replacement of $\mathrm{dmb}$ with dea (Figure 4a) suggests that a dea-based charge-transfer state will be lowest in energy for all dea-containing members of the series. This contrasts with conclusions drawn on the basis of their emission spectra (Figure 4b), which reveal a discontinuous change in the character of the emitting state for $\left[R u(d e a)_{3}\right]^{2+}$ relative to the $d m b-$ containing molecules. Nanosecond time-resolved electronic and infrared absorption data were collected on the entire series; the electronic absorption difference spectra are shown in Figure 5. As described in the following section, the near-UV absorption in the transient spectra of this class of compounds is due to the bipyridyl radical

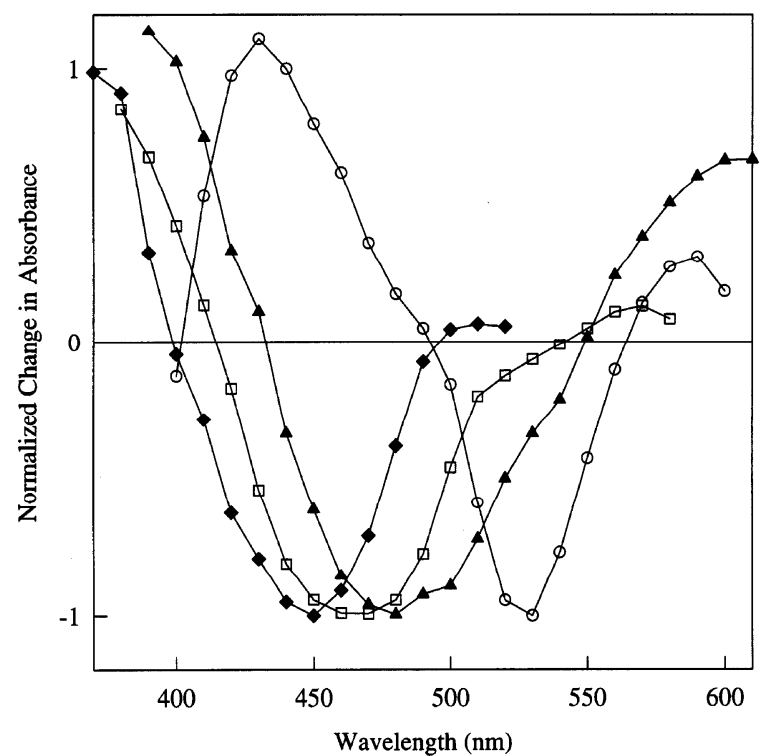

FIGURE 5. Nanosecond time-resolved differential absorption spectra for $\left[\operatorname{Ru}(\mathrm{dmb})_{3}\right]^{2+}(\boldsymbol{\nabla}),\left[\operatorname{Ru}(\mathrm{dmb})_{2}(\mathrm{dea})\right]^{2+}(\square),\left[\operatorname{Ru}(\mathrm{dmb})(\mathrm{dea})_{2}\right]^{2+}(\mathbf{\Delta})$, and $\left[\mathrm{Ru}(\mathrm{dea})_{3}\right]^{2+}(\mathrm{O})$, all in deoxygenated $\mathrm{CH}_{3} \mathrm{CN}$ solution. (Adapted from ref 18.)

anion present in the MLCT excited state. Since the excited state of $\left[\mathrm{Ru}(\mathrm{dea})_{3}\right]^{2+}$ must be dea-based, the fact that the near-UV feature is distinct for this compound (e.g., $\lambda_{\max }$ $=440 \mathrm{~nm}$ versus $\sim 380 \mathrm{~nm}$ for the other three compounds) suggests that the dea- chromophore is unique to [Ru$\left.(\mathrm{dea})_{3}\right]^{2+}$. This in turn implies that the lowest-energy ${ }^{3}$ MLCT state in all three dmb-containing complexes must be dmb-based. In this case, then, the trends inferred upon simple inspection of the absorption spectra led to the wrong conclusions concerning the relative energetics of the ${ }^{3}$ MLCT states across this series. Had we not fully characterized the electronic structure of these compounds using nanosecond spectroscopy prior to ultrafast measurements, the interpretation of the ultrafast dynamics for the mixed-ligand members of this series would have been critically compromised.

Optical Tags for the Charge-Transfer State: Spectroelectrochemistry. Another technique that plays a vital role in laying the groundwork for ultrafast studies of chargetransfer systems is spectroelectrochemistry. Chargetransfer transitions can be thought of as light-induced intramolecular redox reactions. Photoexcitation into an MLCT band, for example, formally results in the oxidation of the metal and reduction of the ligand (eq 1).

$$
\left[\mathrm{M}^{\mathrm{n}+} \mathrm{L}_{6}\right] \underset{\mathrm{MLCT}}{\stackrel{\mathrm{h} v}{\longrightarrow}}\left[\mathrm{M}^{(\mathrm{n}+1)+}\left(\mathrm{L}^{-}\right) \mathrm{L}_{5}\right] *
$$

The absorptive properties of this state can be reasonably approximated by a superposition of the spectra of the oxidized and reduced forms of the molecule (Scheme 1). Spectroelectrochemical data therefore allow the spectroscopic properties of the charge-transfer excited state to be simulated in advance of ultrafast measurements. To illustrate, in Figure 6 are shown data for $\left[\mathrm{Ru}(\mathrm{dpb})_{3}\right]^{2+}$, where $\mathrm{dpb}$ is $4,4^{\prime}$-diphenyl-2,2'-bipyridine. ${ }^{19}$ Oxidation of the molecule eliminates the $\mathrm{Ru}^{\prime \prime}$ species, hence the 


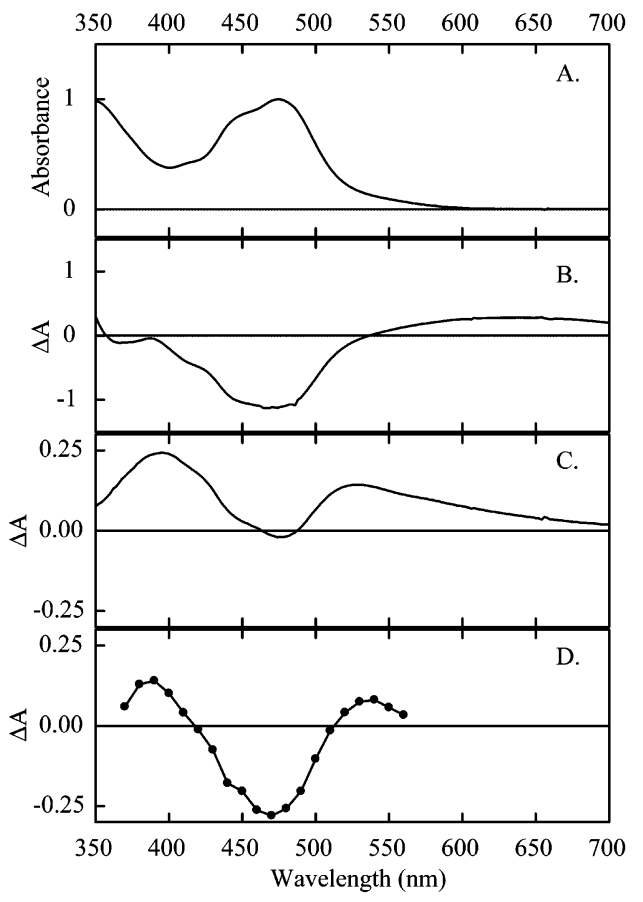

FIGURE 6. Spectroelectrochemical data for $\left[\mathrm{Ru}(\mathrm{dpb})_{3}\right]^{2+}$ in $\mathrm{CH}_{3} \mathrm{CN}$ solution. (A) Electronic absorption spectrum of $\left[\mathrm{Ru}(\mathrm{dpb})_{3}\right]^{2+}$. (B) Oxidative differential absorption spectrum of $\left[\mathrm{Ru}(\mathrm{dpb})_{3}\right]^{2+}$. (C) Reductive differential absorption spectrum of $\left[R u(d p b)_{3}\right]^{2+}$. (D) Nanosecond time-resolved differential absorption spectrum of $\left[\mathrm{Ru}(\mathrm{dpb})_{3}\right]^{2+}$. (Adapted from ref 19.)

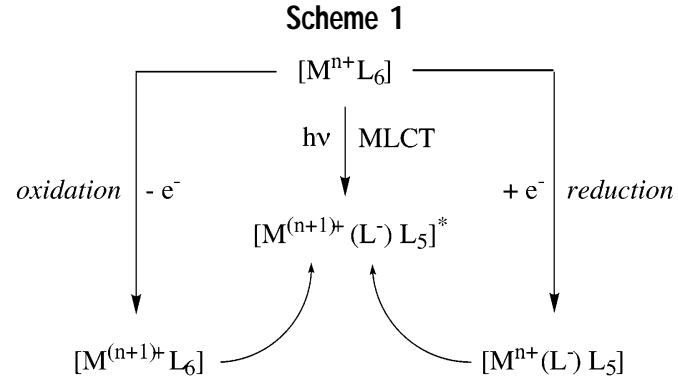

complete loss of absorbance from the MLCT transition in the 450-500 $\mathrm{nm}$ range; the new absorption toward the red is assigned as a LMCT from dpb to Ru'l'. Reduction of the compound creates a $\mathrm{dpb}^{-}$radical species which absorbs in the near-UV as well as in the mid-visible. The nanosecond difference spectrum for $\left[R u(d p b)_{3}\right]^{2+}$ is plotted in the bottom panel: it can be seen quite clearly that the $\mathrm{dpb}^{-}$radical is detected via its absorbances in the near-UV and at $530 \mathrm{~nm}$, whereas contributions from both $\mathrm{dpb}^{-}$and LMCT absorption(s) should be anticipated at $\lambda$ $>600 \mathrm{~nm}$. Given the probe wavelength-dependent nature of dynamics seen on the ultrafast time scale (vide infra), these sorts of assignments of excited-state absorption features can be critical for data interpretation and represent a unique advantage for femtosecond studies of charge-transfer chromophores.

\section{Ultrafast Spectroscopy of Metal Polypyridyls}

Basic Dynamics. The data in Figure 2 illustrate that formation of the ${ }^{3} \mathrm{MLCT}$ excited state in $\left[\mathrm{Ru}(\mathrm{bpy})_{3}\right]^{2+}$ occurs on a subpicosecond time scale; indeed, this appears to be the case for all of the simple Rull polypyridyl complexes we have investigated. The first $\sim 200$ fs of excited-state evolution is likely a convolution of several processes including intersystem crossing, solvent dynamics, and possibly some vibrational cooling. Since the majority of our work has been carried out with $100 \mathrm{fs}$ resolution (as opposed to the $\sim 25$ fs resolution associated with the data in Figure 2), we have not gained significant insight into these initial processes. Largely on the basis of Okada's upconversion experiments ${ }^{11}$ and stimulated emission observed in ultrafast transient absorption measurements by Sundström, ${ }^{20}$ we assume that data we have acquired on the $\sim 100$ fs time scale largely reflect dynamics on the ${ }^{3 M L C T}$ surface (i.e., ISC is presumed to have al ready occurred within our $\sim 100$ fs excitation pulse). It must be stressed that there are data available to support such a conclusion for very few compounds. This assumption must therefore be constantly reexamined until its general ity can be assessed.

Ultrafast transient absorption data on these compounds can be acquired as single-wavelength and fullspectrum data. We take advantage of both by using the former to quantify time constants and the latter to monitor spectral evolution. In principle, full spectrum data collected in sufficiently small time increments can provide the same kinetic information as the single-wavelength measurements through application of global analysis techniques. Two problems associated with this method as applied to ultrafast studies of transition-metal chargetransfer complexes are (1) the relatively small values of $\Delta \epsilon$ that can be encountered with these complexes; and (2) the fact that most of the dynamics we are observing are not associated with changes in the electronic structure of the compound. In the first case, the improved signalto-noise one gets through the use of lock-in detectors for single-wavelength measurements often makes this the only viable approach for quantifying the weak signals observed in certain wavelength regions (e.g., $\Delta \Delta \mathrm{A}<10^{-3}$ ). Second, whereas singular value decomposition (SVD) and/ or global analysis is extremely useful for pulling out the kinetics of spectrally distinct features in the data, it is not clear that dynamics which do not involve significant changes in the overall spectral profile (e.g., vibrational cooling) will yield readily interpretable results. Nevertheless, all of these approaches can be exploited in this research.

Examples of both single-wavelength and full-spectrum data are shown in Figure 7 for $\left[\mathrm{Ru}(\mathrm{dmb})_{3}\right]^{2+}{ }^{2}{ }^{19}$ Whereas ground-state recovery dynamics are independent of the spectral region monitored, we have found that, in general, the kinetics of excited-state formation are extremely sensitive to the probe wavelength chosen (Figure 7a). The utility of spectroelectrochemical data now becomes clear, insofar as it provides us with assignments for the various features being examined. The region dominated by the loss of the Ru" chromophore reveals only an instrumentlimited bleach and no subsequent dynamics prior to ground-state recovery. Since loss of ground-state absorp- 

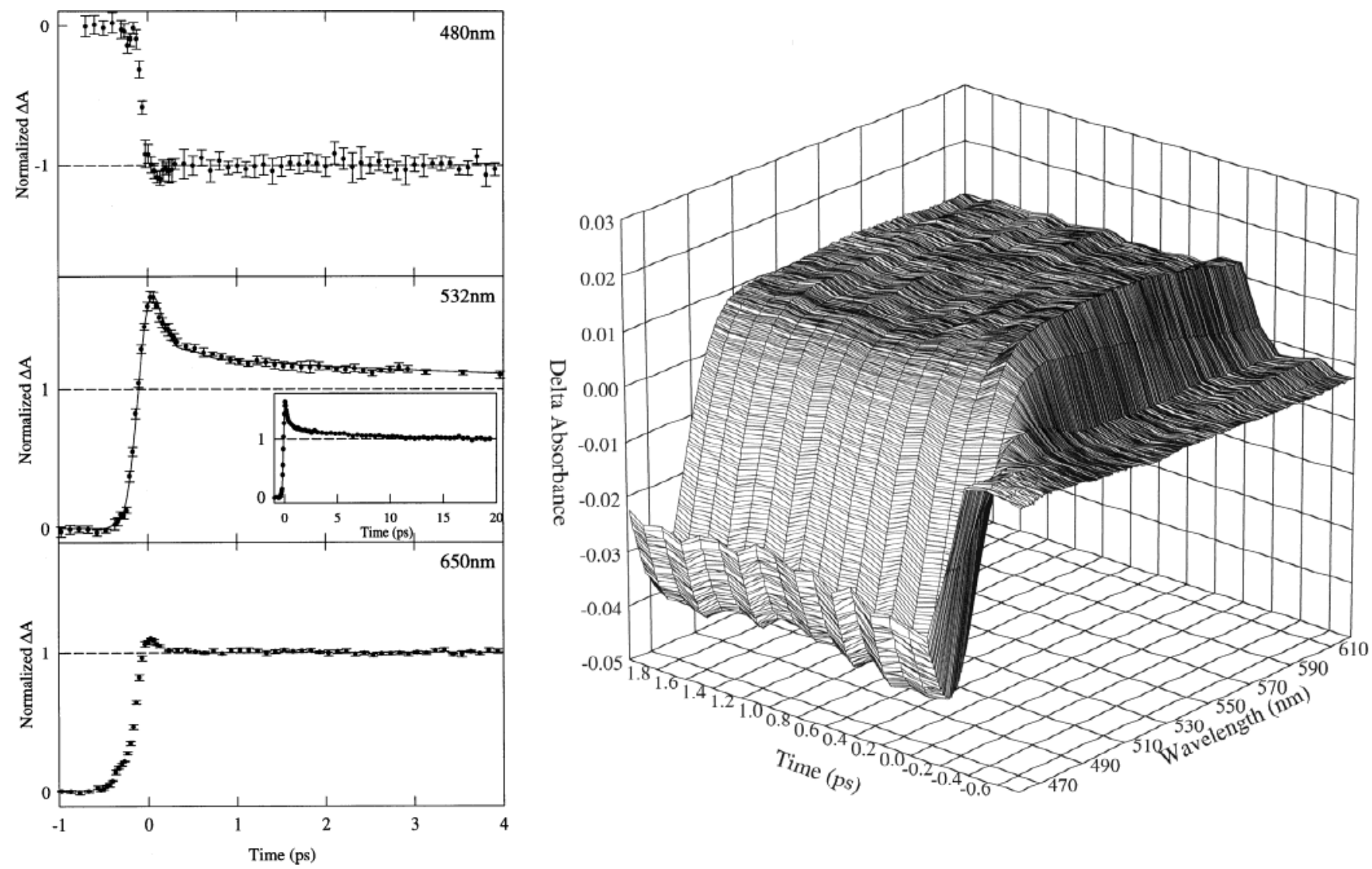

FIGURE 7. (Left) Femtosecond transient absorption difference data for $\left[\mathrm{Ru}(\mathrm{dmb})_{3}\right]^{2+}$ in $\mathrm{CH}_{3} \mathrm{CN}$ solution following $\sim 120 \mathrm{fs}$ excitation at $400 \mathrm{~nm}$. The inset numbers indicate the probe wavelength for each trace. The solid line through the data for $\lambda_{\text {probe }}=532 \mathrm{~nm}$ corresponds to a biexponential fit of the data with time constants of $\tau_{1}=120 \mathrm{~s}$ and $\tau_{2}=5 \mathrm{ps}$. (Right) Transient absorption spectra for $\left[\mathrm{Ru}(\mathrm{dmb})_{3}\right]^{2+}$ in $\mathrm{CH}_{3} \mathrm{CN}$ solution following $\sim 120$ fs excitation at $400 \mathrm{~nm}$. (Adapted from ref 19.)

tion is al ways instantaneous with photon absorption-and returns only once the ground state is reformulateddynamics in probe regions characterized by strong groundstate absorbances are apparent only if excited-state features are intense enough to manifest themselves when superimposed on the bleach. The large oscillator strength of the ${ }^{1} \mathrm{~A}_{1} \rightarrow{ }^{1} \mathrm{MLCT}$ absorption, coupled with the relatively weak excited-state absorptions in the blue region of the spectrum (Figure 6), means that this condition is frequently not met for metal polypyridyls. Thus, transient measurements in the heart of the ground-state bleach are often uninformative for this class of compounds.

Shifting the probe away from the main bleach, however, one begins to detect excited-state dynamics. In [Ru$\left.(\mathrm{dmb})_{3}\right]^{2+}$, kinetics sampling the $\mathrm{dmb}^{-}$radical of the MLCT state at $532 \mathrm{~nm}$ are biphasic in nature. The fast component is a nearly instrument-limited feature that presumably contains the various processes alluded to previously. In addition, there is a 5 ps component evident at this wavelength, after which the data show no additional changes prior to ground-state recovery ( $\tau=850 \mathrm{~ns})$. Given the time scale of these measurements and the possible role of solvent in ultrafast processes (vide infra), it is important to determine whether the observed kinetics at a given probe wavelength are affected by a dynamic Stokes shift (that is, a shift of the absorption spectrum as a function of time through the probe window). While both amplitude changes and spectral shifting provide information on excited-state evolution, their origins and thus the interpretation of the data can be quite different. The fullspectrum data are used in this regard. Inspection of Figure $7 \mathrm{~b}$ shows that there is no shift in the spectral profile over this time window; this is further supported by an SVD analysis of these data, which reveal a single eigenvector with a ca. 5 ps time constant. We can therefore conclude that the kinetics in Figure 7a represent a true change in the amplitude of an otherwise static spectral profile.

If there is no change in the spectral profile of the transient electronic absorption difference spectrum as a function of time, we assume-in the absence of other information-that the observed kinetics are not associated with a significant change in the electronic structure of the molecule In other words, an invariant electronic absorption spectrum is taken to imply invariance in the electronic structure of the molecule. This constitutes an important guiding principle in our analyses of ultrafast data on metal complexes. Clearly, there are no absolutes in this regard: one could envision a change in electronic structure (e.g., an intraconfigurational transition) that may not significantly perturb the excited-state absorption spectrum. In this circumstance, transient absorption may not be sufficient for establishing the nature of the compound's excited-state dynamics. However, given that most excited electronic states are quite distinct from each other 
in terms of their orbital composition, we believe this is a reasonable assumption for providing a starting point in data collection and analysis. In the case of $\left[R u(d m b)_{3}\right]^{2+}$, the lack of any change in the differential absorption spectrum after the first $100 \mathrm{fs}$, coupled with Okada's upconversion results on the closely related $\left[\mathrm{Ru}(\mathrm{bpy})_{3}\right]^{2+}$, strongly suggests that the slower kinetics at $532 \mathrm{~nm}$ are occurring on the lowest-energy ${ }^{3} \mathrm{MLCT}$ surface. By process of elimination, we therefore ascribe the 5 ps component as vibrational cooling of the ${ }^{3} \mathrm{MLCT}$. This indirect method of assigning vibrational relaxation dynamics using electronic absorption spectroscopy has been used successfully by other workers. ${ }^{21}$ However, we are presently pursuing femtosecond infrared measurements to more directly examine the issue of intramolecular vibrational redistribution and relaxation in related charge-transfer compounds.

The lack of any dynamic features at longer probe wavelengths is intriguing. The contrast between the kinetics observed at $532 \mathrm{~nm}$ and the essentially flat response at $650 \mathrm{~nm}$ intimates that the evolution dynamics are highly localized; i.e., the excited-state processes giving rise to the decay features at $532 \mathrm{~nm}$ are associated only with the ligand housing the $\pi^{*}$ electron of the ${ }^{3}$ MLCT state. However, from the spectroelectrochemical data we know that these wavelengths have contributions from both LMCT and $\mathrm{dmb}^{-}$absorptions of the excited state. We have recently carried out more extensive probe-wavelengthdependent studies of the related complex $\left[\mathrm{Ru}(\mathrm{dea})_{3}\right]^{2+} .22$ Measurements farther out to the red, where the deacontribution is negligible, reveal a subtle rise feature having a time constant comparable to the decay measured for the ligand radical. This suggests that time-independent data such as those noted for $\left[\mathrm{Ru}(\mathrm{dmb})_{3}\right]^{2+}$ at $650 \mathrm{~nm}$ may merely reflect a superposition of decay and rise features of two distinct signals in a particular wavelength region.

In addition to probe-wavelength-dependent kinetics, changes in pump wavelength promise to reveal even more dramatic effects. Several groups have noted pump wavelength dependence in the photochemistry of metalcontaining systems. ${ }^{4}$ Results such as these point to differences in pathways for excited-state evolution depending on the nature of the Franck-Condon state formed upon excitation. A simple example from our work is illustrated in Figure 8. Here, the excitation wavelength differs by only $40 \mathrm{~nm}$, yet there is a clearly observable change in the dynamics. A dependence of excited-state evolution on pump wavelength is not surprising, at least in principle. Changes in excitation wavelength can alter the nature of the electronic state initially accessed, which in turn may couple differently with lower-energy excited states. Vibrational cooling rates can likewise be affected as the amount of excess energy that must be dissipated is varied. The origin of the difference in this specific example is still under investigation. However, it is important that the possibility of pump-wavelength-dependent dynamics be kept in mind when comparing results from one laboratory to the next. If the excitation wavelengths employed for various studies are different-especially if they sample distinct absorption features-it is very pos-

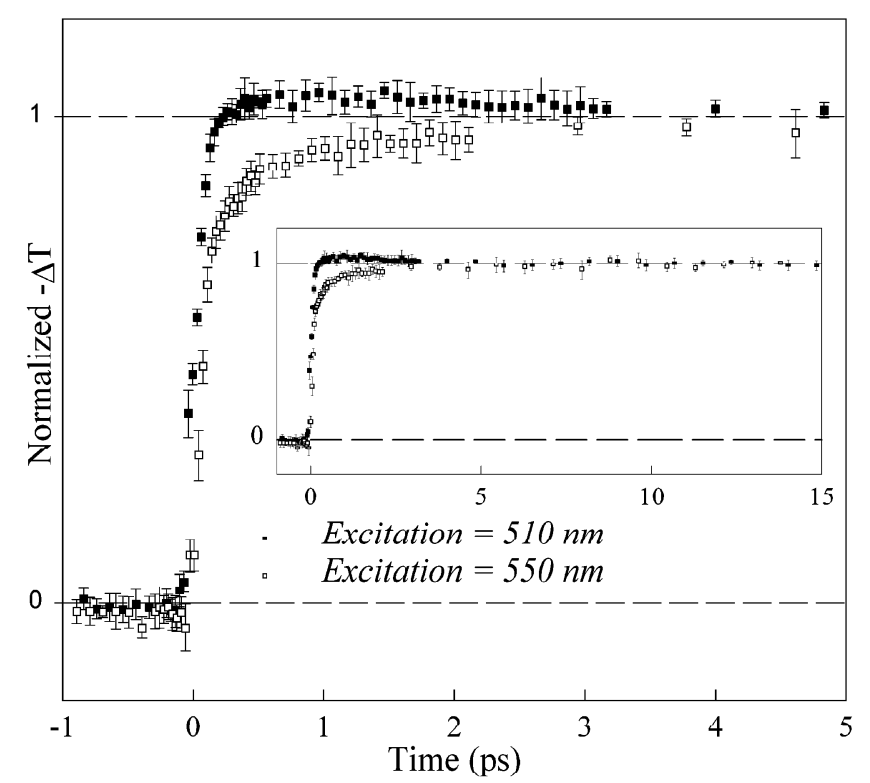

FIGURE 8. Femtosecond transient difference data for $\left[\mathrm{Ru}(\text { dea })_{3}\right]^{2+}$ in $\mathrm{CH}_{3} \mathrm{CN}$ solution following $\sim 120$ fs excitation at the wavelengths indicated. The probe wavelength was $532 \mathrm{~nm}$ in both cases. (Adapted from ref 22.)

sible that the dynamics observed for the same molecule will be different as well.

Large-Amplitude Motion in CT State Formation. The preceding discussion of $\left[\mathrm{Ru}(\mathrm{dmb})_{3}\right]^{2+}$ and related compounds illustrated some of the general features that have begun to emerge in the ultrafast photophysics of simple inorganic charge-transfer complexes. Another compound that we have examined in some detail is the aforementioned $\left[\mathrm{Ru}(\mathrm{dpb})_{3}\right]^{2+}{ }^{19,23}$ Our interest in this system was initially piqued by its anomalously high radiative quantum yield of 0.20 from the ${ }^{3} \mathrm{MLCT}$ state. The emission lifetime of $1.6 \mu \mathrm{s}$ indicates radiative and nonradiative decay rates of $1.25 \times 10^{5}$ and $5.0 \times 10^{5} \mathrm{~s}^{-1}$, respectively; these data contrast with the corresponding values for the dimethyl analogue $\left[\mathrm{Ru}(\mathrm{dmb})_{3}\right]^{2+}\left(\mathrm{k}_{\mathrm{r}}=8.3 \times 10^{4} \mathrm{~s}^{-1}, \mathrm{k}_{\mathrm{nr}}=1.1 \times 10^{6}\right.$ $\mathrm{s}^{-1}$ ), suggesting that the introduction of the aryl group has significantly altered the coupling between the ${ }^{3}$ MLCT state and the ground state. The slight red shift in the emission maximum from $\mathrm{dmb}$ to $\mathrm{dpb}\left(\lambda_{\max }=632\right.$ and $638 \mathrm{~nm}$, respectively), coupled with the increase in $k_{r}$, indicates a substantial increase in the magnitude of the transition dipole for the ${ }^{3} \mathrm{MLCT} \rightarrow{ }^{1} \mathrm{~A}_{1}$ transition in $\left[\mathrm{Ru}(\mathrm{dpb})_{3}\right]^{2+}$. Also significant is the 2 -fold decrease in $k_{n r}$, implying more nested potentials in the case of $\left[R u(d p b)_{3}\right]^{2+}$ relative to $\left[\mathrm{Ru}(\mathrm{dmb})_{3}\right]^{2+} \cdot{ }^{24}$

To explain these observations, we suggested a model in which the aryl rings of the dpb ligand rotate from their canted ground-state geometry toward coplanarity with the bpy plane in the thermalized ${ }^{3} \mathrm{MLCT}$ (Scheme 2). The net effect of this coplanar structure is to allow extended delocalization of the electron in the $\pi^{*}$ orbital of the ligand, which in turn will attenuate the degree of distortion of the $\mathrm{C}-\mathrm{C}$ bonds of the ligand in the excited state and decrease $\mathrm{knr}^{25}$ An analogous change in structure is believed to occur upon reduction of biphenyl; ${ }^{26}$ a similar 
Scheme 2

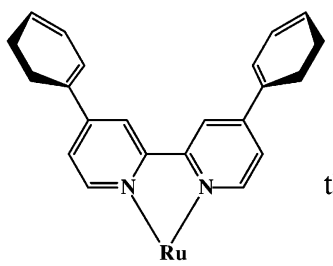

canted

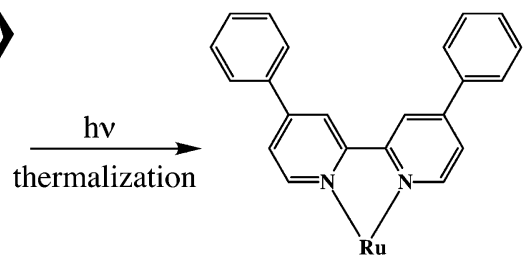

planar delocalization effect had previously been invoked by Meyer and co-workers to explain anomalously long excitedstate lifetimes in certain binuclear Rull complexes. ${ }^{27}$ The extended $\pi$ system of the coplanar state would also increase the magnitude of effective charge separation and lead to a larger transition dipole, thereby increasing $\mathrm{k}_{\mathrm{r}}$. Additional data in support of this model included nanosecond time-resolved resonance Raman spectra. The $\mathrm{C}-\mathrm{C}$ stretch of the bpy ring, which occurs at $1615 \mathrm{~cm}^{-1}$ in the ground state, shifts by $16 \mathrm{~cm}^{-1}$ to $1599 \mathrm{~cm}^{-1}$ in the ${ }^{3} \mathrm{MLCT}$ of $\left[R u(d p b)_{3}\right]^{2+}$. This is substantially less than the $70 \mathrm{~cm}^{-1}$ shift observed for $\left[\mathrm{Ru}(\mathrm{dmb})_{3}\right]^{2+}$ and is consistent with a smaller change in the $\mathrm{C}-\mathrm{C}$ bond strength in the excited state of $\left[\mathrm{Ru}(\mathrm{dpb})_{3}\right]^{2+}$ relative to $\left[\mathrm{Ru}(\mathrm{dmb})_{3}\right]^{2+}$. We also synthesized several analogues of $\mathrm{dpb}$, in which methyl groups were introduced ortho to the 4,4 linkage (Chart 1). Trends in $k_{r}, k_{n r}$, and excited-state resonance Raman data across this series were all consistent with the excitedstate ring rotation hypothesis. ${ }^{23 a}$

Results from computational studies indicate what we might expect from ultrafast studies on $\left[R u(d p b)_{3}\right]^{2+} .23 b$ The principal conclusion can be gleaned from two of these calculations, one for the structurally relaxed anionic form of the ligand and the second for the anion frozen in the ground-state geometry. One can think of the latter as the Franck-Condon state, in which electron transfer to the ligand has occurred but the system has yet to undergo any geometric changes in response to population of the $\pi^{*}$ orbital. The electron density distributions associated with these two conformations for [4-(2,6-dimethyphenyl)pyridine $^{-}$are shown in Figure 9 to illustrate the effect. It can be seen that the large dihedral angle of the ground state $\left(\theta_{\mathrm{i}}=90^{\circ}\right)$ forces initial localization of the $\pi^{*}$ density on the pyridine ring. Once ring rotation ensues (i.e., as the systems evolves in time), the conjugation between the two rings increases, and electron density becomes distributed between the two rings. Given that the visible absorption of the bipyridyl radical anion is polarized along
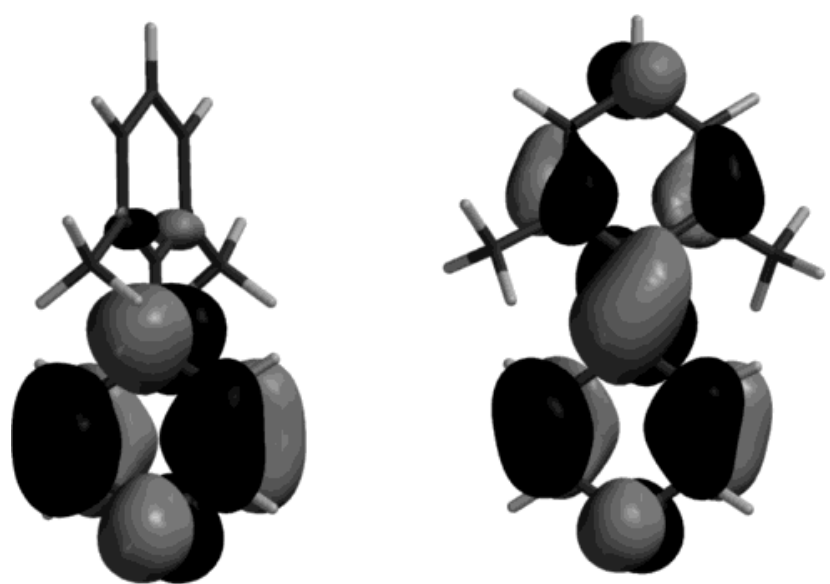

FIGURE 9. Calculated electron densities for the 4-(2,6-dimethylphenyl)pyridine anion. (Left) Geometry optimized for the neutral species. (Right) Fully optimized geometry of the anion. (Adapted from ref 23b.)

the long axis of the molecule (i.e., parallel to the 2,2' carbon-carbon bond), this shift in electron density should be reflected in the time-dependent optical properties of the molecule.

Figure 10 shows femtosecond transient absorption data for $\left[\mathrm{Ru}(\mathrm{dpb})_{3}\right]^{2+}$ in $\mathrm{CH}_{3} \mathrm{CN}$ solution; the compound's spectroelectrochemical properties were described previously (Figure 6). ${ }^{19}$ As with the simpler polypyridyls discussed above, the MLCT bleach region is relatively uninformative, as is the LMCT absorption toward the red. However, wavelengths probing the $\mathrm{dpb}^{-}$radical reveal a significant qualitative difference in the nature of the signal as compared to $\left[\mathrm{Ru}(\mathrm{dmb})_{3}\right]^{2+}$ : instead of a decay in the initial absorbance at $532 \mathrm{~nm}$, the data for $\left[\mathrm{Ru}(\mathrm{dpb})_{3}\right]^{2+}$ correspond to an increase in the absorption cross section of the excited state as a function of time. This is consistent with expectations following the type of shift in electron density discussed above. The kinetics are biphasic, with time constants of $\tau_{1} \approx 200$ fs and $\tau_{2} \approx 2 \mathrm{ps}$, with the latter showing an interesting dependence on the solvent that is discussed in detail elsewhere. ${ }^{28}$ Intersystem crossing to the ${ }^{3}$ MLCT surface is again presumably contained within $\tau_{1}$. The nature of the transient feature at $532 \mathrm{~nm}$ is also strongly dependent on steric factors associated with the aryl substituent, as Figure 11 demonstrates. ${ }^{28}$ From these data, we conclude that we are observing rotation of the aryl ring concomitant with formation and thermalization of the long-lived ${ }^{3} \mathrm{MLCT}$ state. In addition to revealing the time scale of molecular dynamics of this type, this example again illustrates the synergy that can exist among static,

Chart 1

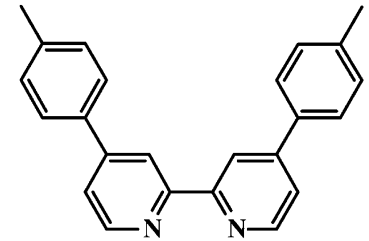

dptb

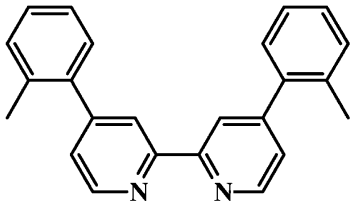

dotb

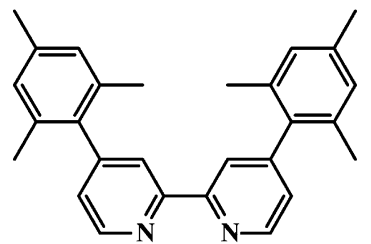

dmesb 


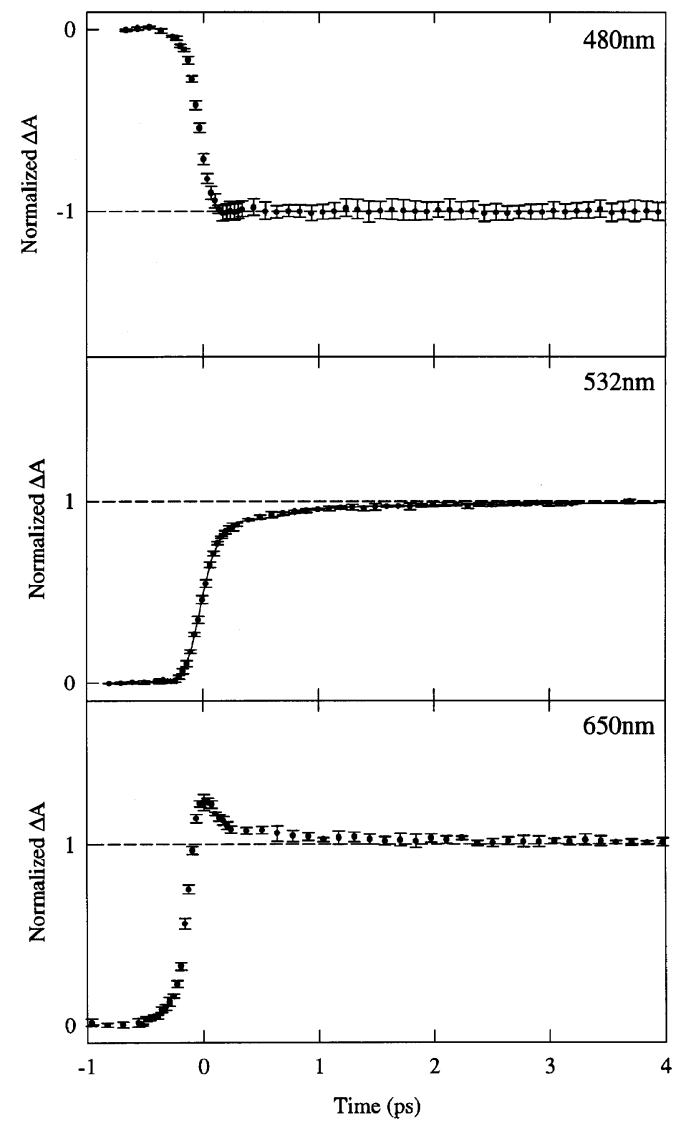

FIGURE 10. Femtosecond transient absorption difference data for $\left[\mathrm{Ru}(\mathrm{dpb})_{3}\right]^{2+}$ in $\mathrm{CH}_{3} \mathrm{CN}$ solution following $\sim 120$ fs excitation at 400 $\mathrm{nm}$. The solid line through the data for $\lambda_{\text {probe }}=532 \mathrm{~nm}$ corresponds to a biexponential fit of the data with time constants of $\tau_{1} \approx 200 \mathrm{fs}$ and $\tau_{2} \approx 2$ ps. (Adapted from ref 19.)

nanosecond, and femtosecond spectroscopic probes, as well as theory, to provide a comprehensive picture of ultrafast excited-state processes.

\section{Solvent Effects}

One characteristic endemic to charge-transfer complexes is the redistribution of charge that accompanies photoexcitation. This is expected to induce dynamics in the solvent due to the change in the local electric field associated with the solute (Scheme 3). The dipole created via photon absorption will initially cause an induced dipole in the solvent (i.e., a polarization response). This will occur essentially instantaneously, prior to any motion of the solvent molecules. As the system evolves in time, the solvent will further readjust to the chromophore's new charge distribution. This will involve, at first, nondiffusive dynamics (e.g., partial rotation of the solvent molecules, the inertial response), followed by larger amplitude rotational and translational motion as the system equilibrates. Depending on the specific solvent in question, the time scale for nondiffusive solvent dynamics falls in the range of 50-500 fs. Diffusive processes are generally much slower, occurring on the order of picoseconds. A far more detailed discussion of solvent dynamics can be found elsewhere. ${ }^{29}$

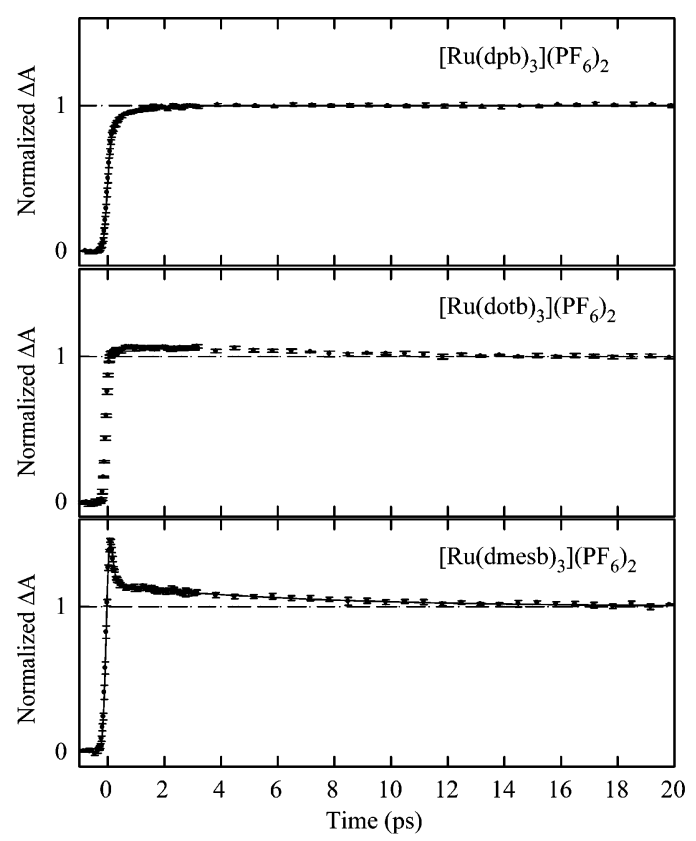

FIGURE 11. Femtosecond transient absorption difference data for $\left[\mathrm{Ru}(\mathrm{dpb})_{3}\right]^{2+}$ (top), $\left[\mathrm{Ru}(\mathrm{dotb})_{3}\right]^{2+}$ (middle), and $\left[\mathrm{Ru}(\mathrm{dmesb})_{3}\right]^{2+}$ (bottom) at $\lambda_{\text {probe }}=532 \mathrm{~nm}$ following $\sim 120 \mathrm{fs}$ excitation at $400 \mathrm{~nm}$. All of the data were acquired in $\mathrm{CH}_{3} \mathrm{CN}$ solution. (Adapted from ref 28.)

We can adapt this same picture to help us envision solvent response to a charge-transfer excitation. For compounds such as $\left[\mathrm{Ru}(\mathrm{bpy})_{3}\right]^{2+}$, polar molecules such as $\mathrm{CH}_{3} \mathrm{CN}$ will strongly solvate the complex. An MLCT excitation corresponds to the transfer of an electron from the core of the molecule to its periphery. The consequence of this in the present case is an effective inversion of the sign of the charge with which the solvent is interacting. Given this and the time scale of solvent response, it is reasonable to expect that solvent dynamics may couple to or otherwise influence the ultrafast excited-state processes we are examining. It is important to emphasize that our goal is not to probe solvent dynamics per se, but rather to take what is known about solvent dynamics and assess what effect they may be having on charge-transfer state formation and thermalization.

\section{Scheme 3}

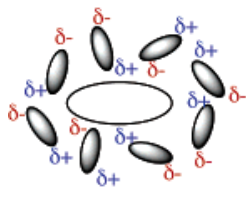

random solvent orientation

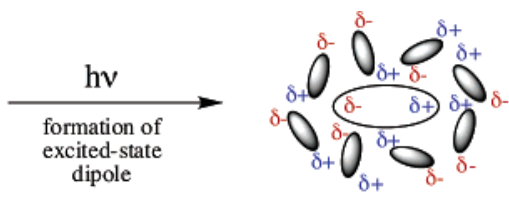

random solvent orientation: Franck-Condon state

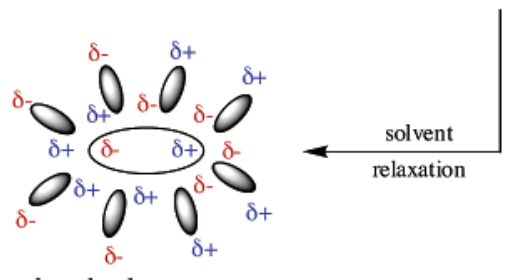

ordered solvent structure around excited-state dipole 


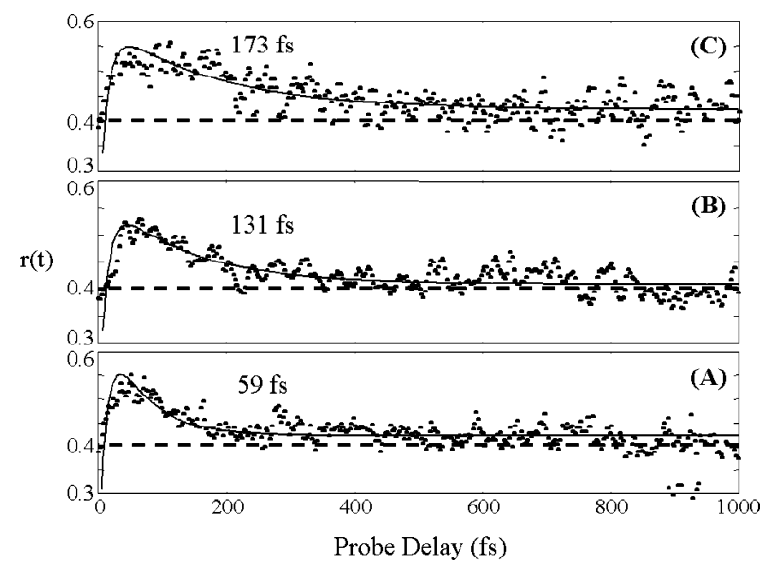

FIGURE 12. Transient absorption anisotropy data for $\left[\mathrm{Ru}(\mathrm{bpy})_{3}\right]^{2+}$ at $480 \mathrm{~nm}$ collected in $\mathrm{CH}_{3} \mathrm{CN}(\mathrm{A}), \mathrm{CH}_{3} \mathrm{CH}_{2} \mathrm{CN}(\mathrm{B})$, and $\mathrm{CH}_{3}\left(\mathrm{CH}_{2}\right)_{2} \mathrm{CN}$ (C) solutions following $\sim 30$ fs excitation at $480 \mathrm{~nm}$. The numbers indicate time constants from single-exponential fits of each data set and should be considered as having error bars of $\sim 10 \%$. (Adapted from ref 30 .)

Our initial results indicate that solvent dynamics do, in fact, play a role in the excited-state evolution of inorganic charge-transfer systems. We illustrate this here with a single example. This work originated from an examination of excited-state localization/delocalization in $\left[\mathrm{Ru}(\mathrm{bpy})_{3}\right]^{2+} .30,31$ For now we need only mention that the relevant data derive from femtosecond absorption anisotropy studies of $\left[\mathrm{Ru}(\mathrm{bpy})_{3}\right]^{2+}$. In this experiment, polarized excitation of the sample is followed by measurement of the sample's excited-state absorbance with the probe beam polarized parallel $\left(I_{\|}\right)$and perpendicular $\left(I_{\perp}\right)$ to the pump. These data are then normalized to the isotropic signal (i.e., population dynamics) to yield the absorption anisotropy $r(t)$ (eq 2).

$$
r(t)=\frac{I_{\|}-I_{\perp}}{I_{\| 1}+2 I_{\perp}}
$$

The data acquired at a probe wavelength of $480 \mathrm{~nm}$ in $\mathrm{CH}_{3} \mathrm{CN}$ solution following $\sim 30 \mathrm{fs}$ excitation at $480 \mathrm{~nm}$ revealed that the symmetry of the MLCT excited state changed as a function of time. The data are consistent with a state of $\mathrm{C}_{3}$ (or higher) symmetry relaxing to a state of $\mathrm{C}_{2}$ (or lower) symmetry with $\tau \approx 60 \mathrm{fs}$. This observation was interpreted as a delocalized-to-localized transition in which an excited state of $D_{3}$ symmetry evolved to a chargelocalized configuration of $\mathrm{C}_{2}$ symmetry (eq 3 ).

$$
\begin{array}{r}
{\left[\mathrm{Ru}^{\prime \prime}(\mathrm{bpy})_{3}\right]^{2+} \underset{\tau<30 \mathrm{fs}}{\mathrm{h} v}\left[\mathrm{Ru}^{\prime \prime \prime}\left(\mathrm{bpy}^{-1 / 3}\right)_{3}\right]^{2+} \stackrel{\tau \approx 60 \mathrm{fs}}{\longrightarrow}} \\
{\left[\mathrm{Ru}^{\prime \prime \prime}\left(\mathrm{bpy}^{-}\right)(\mathrm{bpy})_{2}\right]^{2+}}
\end{array}
$$

The time constant for this charge localization process is notable, in that $60 \mathrm{fs}$ is roughly the time scale for the inertial response of $\mathrm{CH}_{3} \mathrm{CN} .{ }^{32}$ To determine whether inertial response dynamics were in fact coupled to charge localization, we carried out the same measurement in propionitrile and butyronitrile: these data are illustrated in Figure $12 .{ }^{30}$ It can be seen that, as the inertial mass of the solvent increases, so too does the time scale for charge localization. The value of $\sim 130$ fs for $\mathrm{CH}_{3} \mathrm{CH}_{2} \mathrm{CN}$ is similar to what has been observed for the inertial dynamics of this solvent. ${ }^{33}$ Although an inertial response time for butyronitrile has not been reported, the trend across the solvent series is nevertheless compelling. Of course, additional data on a wider range of chemical systems are needed, but our assessment at present is that nondiffusive solvent dynamics are an important factor in the early stages of charge-transfer state evolution of transition metal chromophores in the condensed phase.

\section{Concluding Comments}

Prior to the advent of ultrafast spectroscopy, models describing the mechanism of excited-state evolution relied on assumptions concerning the relative rates of various processes. The underlying rationale for these assumptions is straightforward. Vibrational relaxation, which occurs on the time scale of bond vibrations and does not involve a change in the electronic structure of the molecule (i.e., no surface crossing), is presumed to be the fastest initial process. Excitation into a given electronic excited state is therefore followed first by thermalization. As time progresses, conversion to lower-energy electronic states can occur. Keying on the notion that processes for which $\Delta \mathrm{S} \neq 0$ are formally forbidden, internal conversion is presumed to occur next. If there exist states of differing spin multiplicity at lower energy, intersystem crossing can be expected at a substantially slower rate. This model therefore creates a cascade picture for excited-state evolution based on the assumption that $\mathrm{k}_{\text {vib }} \gg \mathrm{k}_{\mathrm{IC}} \gg \mathrm{k}_{\mathrm{ISC}}$.

Given the relatively small spin-orbit coupling and high-frequency vibrational modes typical of most organic chromophores, this model is a reasonable starting point for interpreting their photophysics. However, the introduction of an open-shell transition metal represents an enormous perturbation to the electronic structure of a molecule that has no counterpart in organic photochemistry. It is therefore not immediately obvious that inorganic compounds should behave in a manner similar to organic systems. That being stated, the fields of inorganic photophysics and photochemistry have clearly benefited from guidelines such as those just described, providing a foundation for the interpretation of longer time scale dynamics of inorganic compounds. The process of excitedstate evolution, on the other hand, where a much larger number of electronic and vibrational states can couple to the relaxation process, is an entirely different situation. We have admittedly sampled only a limited number of transition-metal systems. Nevertheless, we have yet to find a transition-metal complex whose excited-state evolution dynamics conforms to the picture just outlined. In fact, there is little justification based on any data of which we are aware for assigning the nature of a given photophysical process in an inorganic system solely on the basis of its absolute (or relative) rate. For example, in other work we have shown that charge-transfer to ligand-field state conversion following ${ }^{1} \mathrm{~A}_{1} \rightarrow{ }^{1} \mathrm{MLCT}$ excitation of an Fe polypyridyl complex occurs with a time constant of $80 \pm$ 
$20 \mathrm{fs}^{34}$ Subsequent formation of the ${ }^{5} \mathrm{~T}_{2}$ ligand-field state (the lowest-energy excited state of the system) is complete in $\ll 1$ ps: overall, this corresponds to a process that is formally $\Delta S=2$, occurring more than an order of magnitude faster than vibrational cooling. As previously mentioned, intersystem crossing in $\left[\mathrm{Ru}(\mathrm{bpy})_{3}\right]^{2+}$ occurs in $40 \pm 15 \mathrm{fs}^{11}$ whereas vibrational cooling is observed on a time scale of several picoseconds. ${ }^{19}$ The point we wish to emphasize is that ascribing the origin of kinetic features on the basis of a presumption of what the relative magnitudes of various processes "should" be is, in our opinion, wholly unjustified when dealing with excitedstate evolution in transition-metal chromophores. This raises the bar in terms of the amount of information one must acquire in order to construct a viable model for dynamics on ultrafast time scales, but it is critically important that these sorts of criteria be applied to efforts now while protocols for this type of research are still being established.

Throughout the course of our work in this area, we have chosen probe molecules simple enough to allow for unambiguous data interpretation, yet relevant enough to form the basis for future studies on more chemically interesting systems. The research that has been described in this Account makes it clear that the set of rules upon which models for inorganic photophysics have been based does not apply when it comes to describing excited-state evolution. It is equally clear that a new set of rules defining inorganic photophysics on ultrafast time scales has yet to emerge. The tool for directly examining the initial events following photoexcitation-femtosecond spectroscopy-has been widely available for little more than a decade. As a consequence, virtually every ultrafast measurement carried out on an inorganic system represents new information, and inorganic chemistry provides an enormously rich variety of molecules for study. A survey of the current literature suggests that researchers are beginning to avail themselves of the opportunities that exist in this area. We can therefore expect that in the coming years an interesting and exciting new chapter in the field of inorganic photophysics will be written.

This research has been generously supported through grants from the Office of Basic Energy Sciences, U.S. Department of Energy. The author would also like to thank the students whose hard work this paper represents, as well as a number of colleagues for many fruitful discussions.

\section{References}

(1) (a) Stoddart, J . F. Molecular Machines. Acc. Chem. Res. 2001, 34, 410-411. (b) Balzani, V.; Credi, A.; Raymo, F. M.; Stoddart, J . F. Artificial molecular machines. Angew. Chem., Int. Ed. 2000, 39, 3348-3391.

(2) Photochemistry and Radiation Chemistry: Complementary Methods for the Study of Electron Transfer, Wishart, J . F., Nocera, D. G., Eds.; ACS Advances in Chemistry Series 254; American Chemical Society: Washington, DC, 1998.

(3) (a) Kalyanasundaram, K.; Gratzel, M. Applications of functionalized transition metal complexes in photonic and optoelectronic devices. Coord. Chem. Rev. 1998, 177, 347-414. (b) Balzani, V.; Credi, A.; Scandola, F. Supramolecular photochemistry and photophysics. Energy-conversion and information-processing devices based on transition metal complexes. NATO ASI Ser., Ser. C: Math. Phys. Sci. 1994, 448, 1-32.
(4) (a) Farrell, I. R.; Matousek, P.; Towrie, M.; Parker, A. W.; Grills, D. C.: George, M. W.: Vlcek, A. J r. Direct observation of competitive ultrafast CO dissociation and relaxation of an MLCT excited state: Picosecond time-resolved infrared spectroscopic study of [Cr(CO)4(2,2'-bipyridine)]. Inorg. Chem. 2002, 41, 4318-4323 and references therein. (b) Shiang, J . J .; Walker, L. A., Il; Anderson, N. A.; Cole, A. G.; Sension, R. J . Time-Resolved Spectroscopic Studies of B12 Coenzymes: The Photolysis of Methylcobalamin Is Wavelength Dependent. J. Phys. Chem. B 1999, 103, 1053210539.

(5) Balzani, V.; Campagna, S.; Denti, G.; J uris, A.; Serroni, S.; Venturi, M. Designing Dendrimers Based on Transition-Metal Complexes. Light-Harvesting Properties and Predetermined Redox Patterns. Acc. Chem. Res. 1998, 31, 26-34.

(6) (a) Buchs, M.; Daul, C. Geometry optimization and excited states of tris(2,2'-bipyridine)ruthenium(II) using density functional theory. Chimia 1998, 52 (4), 163-166. (b) Kober, E. M.; Meyer, T. J . An electronic structural model for the emitting MLCT excited states of $\left[\mathrm{Ru}(\mathrm{bpy})_{3}\right]^{2+}$ and $\left[\mathrm{Os}(\mathrm{bpy})_{3}\right]^{2+}$. Inorg. Chem. 1984, 23, 38773886.

(7) Yabe, T.; Anderson, D. R.; Orman, L. K.; Chang, Y.J .; Hopkins, J. B. Picosecond dynamics of solvent trapping following electron transfer in transition-metal complexes. J. Phys. Chem. 1989, 93, 2302-2306 and references therein.

(8) Damrauer, N. H.; Cerullo, G.; Yeh, A.; Boussie, T. R.; Shank, C. V.; McCusker, J . K. Femtosecond Dynamics of Excited-State Evolution in $\left[\mathrm{Ru}(\mathrm{bpy})_{3}\right]^{2+}$. Science 1997, 275, 54-57.

(9) The value of $\tau \approx 100$ fs is an approximation based on an assumption that spectral changes will be observed for roughly $2-3$ half-lives of the state being probed.

(10) Each spin manifold has its own set of excited states, so singletsinglet absorptions can arise from the ${ }^{1} \mathrm{MLCT}$, triplet-triplet from the ${ }^{3} \mathrm{MLCT}$, and so on. It is not known a priori to what extent the spectral profiles associated with these spin manifolds will differ.

(11) Bhasikuttan, A. C.; Suzuki, M.; Nakashima, S.; Okada, T. Ultrafast Fluorescence Detection in Tris(2,2'-bipyridine)ruthenium(II) Complex in Solution: Relaxation Dynamics Involving Higher Excited States. J. Am. Chem. Soc. 2002, 124, 8398-8405.

(12) Extinction coefficients derived from Beer's law are more routinely used in this regard.

(13) Kober, E. M.; Meyer, T. J . Concerning the absorption spectra of the ions $\left[\mathrm{M}(\mathrm{bpy})_{3}\right]^{2+}(\mathrm{M}=\mathrm{Fe}, \mathrm{Ru}, \mathrm{Os}$; bpy = 2,2'-bipyridine). Inorg Chem. 1982, 21, 3967-3977.

(14) For a good general reference on DFT, see: Bickelhaupt, F. M.; Baerends, E. J . Kohn-Sham density functional theory: predicting and understanding chemistry. Rev. Comput. Chem. 2000, 15, $1-86$.

(15) Monat, J. E.; Rodriguez, J . H.; McCusker, J. K. Ground- and Excited-State Electronic Structure of the Solar Cell Sensitizer bis(4,4'-dicarboxylato-2,2'-bipyridine)bis(isothiocyanato)ruthenium(II). J. Phys. Chem. A 2002, 106, 7399-7406.

(16) Kuciauskas, D.; Monat, J . E.; Villahermosa, R.; Gray, H. B.; Lewis, N. S.; McCusker, J . K. Electron Injection Dynamics of Ruthenium and Osmium Polypyridyl Complexes Adsorbed Onto Nanocrystalline $\mathrm{TiO}_{2}$ Photoelectrodes. J. Phys. Chem. B 2002, 106, 93479358

(17) Daniel, C. Quantum chemistry and Dick Stufkens photochemistry. Coord. Chem. Rev. 2002, 230 (1-2), 65-78 and references therein

(18) Curtright, A. E.; McCusker, J. K. Static and Time-Resolved Spectroscopic Studies of Low-Symmetry Ru(II) Polypyridyl Complexes. J. Phys. Chem. A 1999, 103, 7032-7041.

(19) Damrauer, N. H.; McCusker, J . K. Ultrafast Dynamics in the Metalto-Ligand Charge Transfer State Evolution of [Ru(4,4'-diphenyl2,2'-bipyridine) $\left.3_{3}\right]^{2+}$. J. Phys. Chem. A 1999, 103, 8440-8446.

(20) Benko G.; Myllyperkio P.; Pan J .; Yartsev, A. P.; Sundstrom, V. Photoinduced electron injection from Ru(dcbpy $)_{2}(\mathrm{NCS})_{2}$ to $\mathrm{SnO}_{2}$ and $\mathrm{TiO}_{2}$ nanocrystalline films. J. Am. Chem. Soc. 2003, 125, 1118-1119 and references therein

(21) (a) Eom, H. S.; J eoung, S. C.; Kim, D.; Ha, J .-H.; Kim, Y.-R. Ultrafast Vibrational Relaxation and Ligand Photodissociation/Photoassociation Processes of Nickel(II) Porphyrins in the Condensed Phase. J. Phys. Chem. A 1997, 101, 3661-3669. (b) King, J . C.; Zhang, J . Z.; Schwartz, B. J .; Harris, C. B. Vibrational relaxation of transition metal $(\mathrm{M})$ carbonyls $\left(\mathrm{M}(\mathrm{CO})_{6}\right)(\mathrm{M}=$ chromium, molybdenum, tungsten): effect of metal mass on vibrational cooling dynamics and non-Boltzmann internal energy distributions. J . Chem. Phys. 1993, 99 (10), 7595-7601 and references therein

(22) Curtright, A. E. Excited-State Electronic Structure and Dynamics of Asymmetric Ruthenium Bipyridyl Complexes. Ph.D. Thesis, University of California at Berkeley, May 2003.

(23) (a) Damrauer, N. H.; Boussie, T. R.; Devenney, M.; McCusker, J. K. Effects of Intraligand Electron Delocalization, Steric Tuning, and Excited-State Vibronic Coupling on the Photophysics of ArylSubstituted Bipyridyl Complexes of Ru(II). J. Am. Chem. Soc. 
1997, 119, 8253-8268. (b) Damrauer, N. H.; Weldon, B. T.; McCusker, J . K. Theoretical Studies of Steric Effects on Intraligand Electron Delocalization: Implications for the Temporal Evolution of MLCT Excited States. J. Phys. Chem. A 1998, 102, 3382-3397. (c) Damrauer, N. H.; McCusker, J . K. Variable-Temperature Emission Studies of Solvation Dynamics: Evidence for Coupling of Solvation to Chromophore Structural Dynamics in the Evolution of Charge-Transfer Excited States. Inorg. Chem. 1999, 38, 42684277.

(24) J ortner, J .; Rice, S. A.; Hochstrasser, R. M. Radiationless transitions in photochemistry. Adv. Photochem. 1969, 7, 149-309.

(25) The $C-C$ stretch of the bpy ring is a dominant mode for vibronic coupling of the ${ }^{3} \mathrm{MLCT} \rightarrow{ }^{1} \mathrm{~A}_{1}$ relaxation.

(26) (a) Almenningen, A.; Bastiansen, O.; Fernholt, L.; Cyvin, B. N.; Cyvin, S. J .; Samdal, S. Structure and barrier of internal rotation of biphenyl derivatives in the gaseous state. Part 1. The molecular structure and normal coordinate analysis of normal biphenyl and perdeuterated biphenyl. J. Mol. Struct. 1985, 128 (1-3), 59-76. (b) Furuya, K.; Torii, H.; Furukawa, Y.; Tasumi, M. Density functional study on the structures and vibrational spectra of the radical anion and cation of biphenyl. Theochem 1998, 424 (3), 225-235.

(27) Strouse, G. F.; Schoonover, J . R.; Duesing, R.; Boyde, S.; J ones, W. E., J r.; Meyer, T. J . Influence Of Electronic Delocalization In
Metal-to-Ligand Charge-Transfer Excited States. Inorg. Chem. 1995, 34, 473-487.

(28) Damrauer, N. H.; Curtright, A. E.; McCusker, J . K. Solvent and Structual Dependence of Primary Relaxation Processes in Arylated Bipyridyl Complexes of Ruthenium(II). Submitted for publication.

(29) Stratt, R. M.; Maroncelli, M. Nonreactive Dynamics in Solution: The Emerging Molecular View of Solvation Dynamics and Vibrational Relaxation. J. Phys. Chem. 1996, 100, 12981-12996.

(30) Yeh, A. T.; Shank, C. V.; McCusker, J. K. Ultrafast Electron Localization Dynamics Following Photo-Induced Charge Transfer. Science 2000, 289, 935-938.

(31) McCusker, J. K.; Papanikolas, J. M. (Possibly) The Last Word on the First Events Following Photoexcitation of $\left[\mathrm{M}(\mathrm{bpy})_{3}\right]^{2+}(\mathrm{M}=$ $\mathrm{Ru}, \mathrm{Os})$. Manuscript in preparation.

(32) Passino, S. A.; Nagasawa, Y.; J oo, T.; Fleming, G. R. Three-Pulse Echo Peak Shift Studies of Polar Solvation Dynamics. J. Phys. Chem. A 1997, 101, 725-731.

(33) Maroncelli, M. Personal communication.

(34) Monat, J . E.; McCusker, J . K. Femtosecond Excited-State Dynamics of an Iron(II) Polypyridyl Solar Cell Sensitizer Model. J. Am. Chem. Soc. 2000, 122, 4092-4097.

AR030111D 